\title{
Development and Analysis of the Wind Power Industry in Xinjiang, China
}

\author{
Shuai $\mathrm{Li}^{1}$, Lubing Xie ${ }^{1} \&$ Xiaoming Rui ${ }^{1}$ \\ ${ }^{1}$ School of Energy, Power and Mechanical Engineering, North China Electric Power University, Beijing, China \\ Correspondence: Lubing Xie, School of Energy, Power and Mechanical Engineering, North China Electric \\ Power University, Beijing, China.
}

\author{
Received: April 7, 2018 Accepted: April 30, 2018 Online Published: May 16, 2018 \\ doi:10.5539/jms.v8n2p51 URL: https://doi.org/10.5539/jms.v8n2p51
}

\begin{abstract}
As one of the energy bases of China, Xinjiang Uygur Autonomous Region has participated in a series of developing programs, such as The Western Development (2000), The Belt and the Road (2014), and The Global Energy Internet Strategy (2015), which signify that China places considerable importance to the sustainable development of the energy industry in Xinjiang. As an important part of the energy industry in Xinjiang, the emerging wind power industry in this region has developed rapidly in recent years. However, many problems have emerged, such as the abandoned wind power rationing, which seriously restricts the healthy development of the wind power industry. In this study, we introduce the development of the renewable energy industry and analyze the wind energy resources in Xinjiang. We mainly investigate the development situation and existing problems in the wind power industry. Then we focus on the problem of wind power curtailment, analyze the causes, and propose measures and strategies to alleviate this problem. Our findings will contribute to the sustainable development of the wind power industry in Xinjiang.
\end{abstract}

Keywords: wind power industry, Xinjiang, wind power curtailment

\section{Introduction}

Xinjiang is located in northwest China and characterized by varying surface topography and abundant energy resources. The area of $1.66 \times 10^{6} \mathrm{~km}^{2}$ makes Xinjiang the largest province in China. Its abundant fossil fuel reserves of coal, oil and natural gas rank third in China, and its renewable energy resources, including wind energy and solar energy, are among the highest in China. Xinjiang has been listed as one of the five comprehensive strategic energy bases in China. The National Development and Reform Commission in 2006 identified three major oil fields in Xinjiang. In 2010, Xinjiang was listed among the nine wind power bases in China. In 2013, it was ranked as the fourteenth largest coal base in China. In 2014, the national development strategy, called the Belt and the Road, involved Xinjiang as one of its core areas. The Central Xinjiang Development Forum established a clear development path of the energy industry in Xinjiang, named "three bases and one channel", which includes the "three bases" of large coal, oil/gas, and wind power bases, and "one channel" of national land energy channel (Fan et al., 2016, p.4).

To achieve clean and sustainable development of the energy industry in Xinjiang, the state places considerable importance to the development of wind energy in Xinjiang. The state also supports wind farm construction in Hami and Dabancheng, and promotes the development of a national large-scale wind power base in Xinjiang (Guo et al., 2015, p.5).

The development of wind power in Xinjiang has been progressing rapidly since 2009. In 2013, the installed capacity of wind power grids overtook that of hydropower. By 2014, the grid capacity of wind power ranked first among potential renewable energy sources in Xinjiang (Fig. 1). In 2014, the cumulative power generation in Xinjiang increased by $30.16 \%$. Wind power generation capacity $(135.47 \mathrm{kWh})$ accounted for $6.89 \%$ of the total power generation (Fig. 2). The proportion of wind power in the total power generation of Xinjiang has been increasing annually and maintained a good momentum of economic development. By 2014, the total installed capacity of power supply in Xinjiang reached $55486 \mathrm{MW}$, of which $14.47 \%$ came from wind power (8030 MW). The structure of the power assembly machine capacity in Xinjiang is shown in Fig. 3 (Heya et al., 2015). The capacity of new energy grids in Xinjiang accounted for nearly $30 \%$ of total power capacity, with the highest proportion of $14.47 \%$ coming from wind power (Fig. 3). The installed capacities of wind power in Xinjiang from 
2010 to 2014 are presented in Fig. 4. The installed capacity of grid-connected wind power increases annually in Xinjiang (Fig. 4), which indicates the rapid development of the wind power industry.

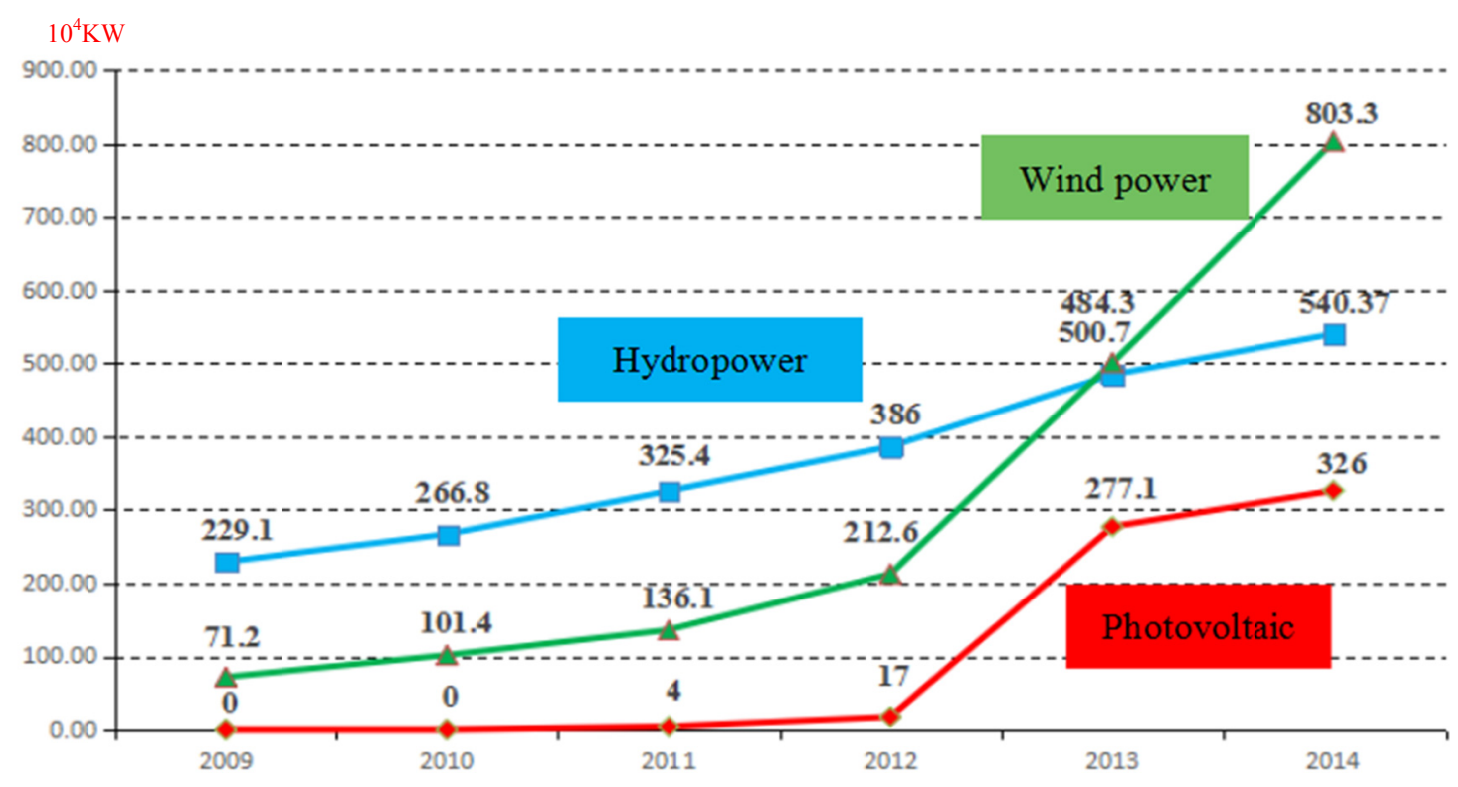

Figure 1. Situation of renewable energy grids in Xinjiang $\left(2009-2014,10^{4} \mathrm{~kW}\right)$

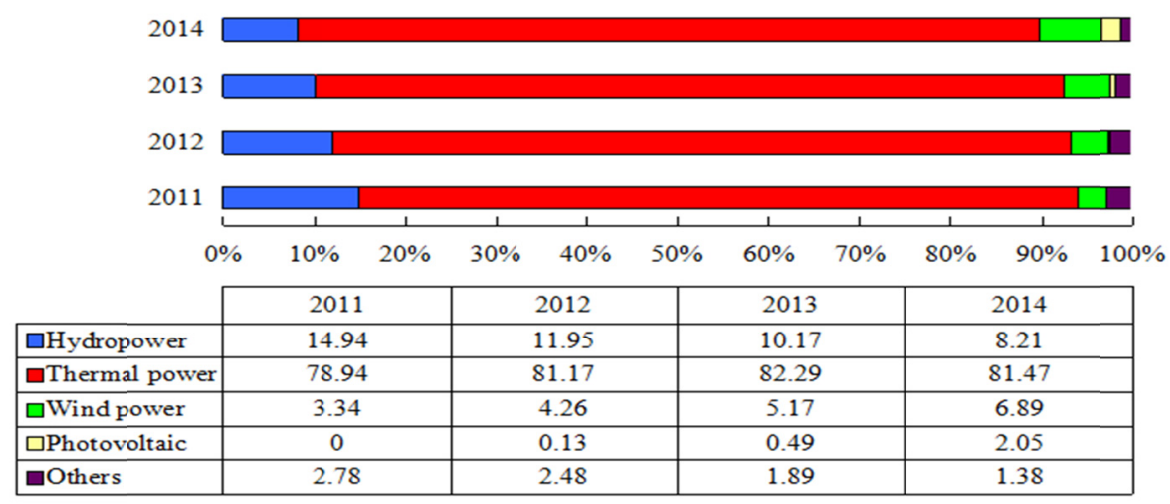

Figure 2. Power generation situation in Xinjiang (2011-2014)

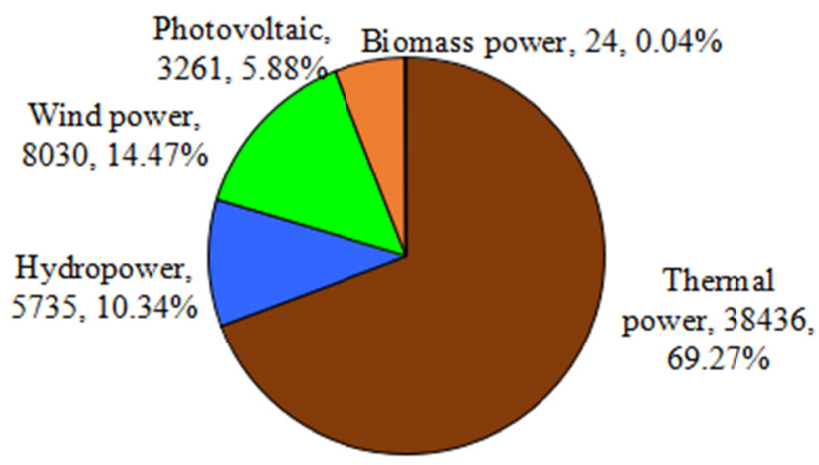

Figure 3. Structure of the total installed capacity (MW) of grid connections in Xinjiang in 2014 


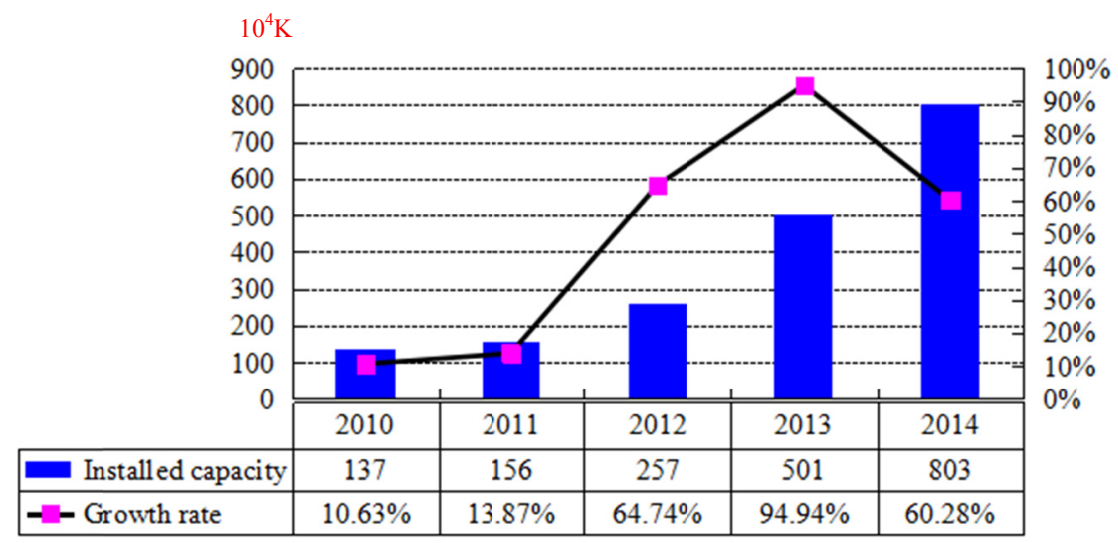

Figure 4. Wind power installed capacity in Xinjiang $\left(2010-2014,10^{4} \mathrm{~kW}\right)$

Along with the rapid development, however, many problems have emerged, such as the abandoned wind power rationing that has seriously restricted the healthy development of wind power in Xinjiang.

In this study, we analyzed the current situations of wind energy resources and the wind power industry in Xinjiang, including the development trends and problems. A comprehensive evaluation system for wind power utilization was established, with the wind power base in Hami as an example. The wind power utilization level was analyzed via the improved analytic hierarchy and fuzzy comprehensive evaluation. Abandoned wind power cuts in Xinjiang require in-depth analysis, so we proposed some measures and strategies to alleviate such cuts. The findings of this study will help to realize the healthy and sustainable development of wind power in Xinjiang.

\section{Wind Power Profile in Xinjiang}

\subsection{Wind Energy Resources}

Xinjiang has abundant wind energy resources, with the total reserves of $8.9 \times 10^{8} \mathrm{~kW}$, about $20.4 \%$ of total reserves in China. The installed capacity of wind power in this region is over $1.2 \times 10^{8} \mathrm{~kW}$, which is 5.4 times that of the Three Gorges Hydropower Station (22.4 million $\mathrm{kW}$ ). Xinjiang also generates over $1.8 \times 10^{11} \mathrm{kWh}$ wind power, which ranks second in China (Gosens et al., 2013).

The vast mountain and valley areas as well as various fan-shaped and plain landforms in Xinjiang have constituted nine wind resource areas (Fig. 5): Urumqi Dabancheng, Xiaocaohu, southeast Hami, Santanghu Nao Mao Hu, Hami 13-room, Irtysh River Valley, Alashankou, old Tacheng, and Lop Nur wind zones (Huber et al., 2015).

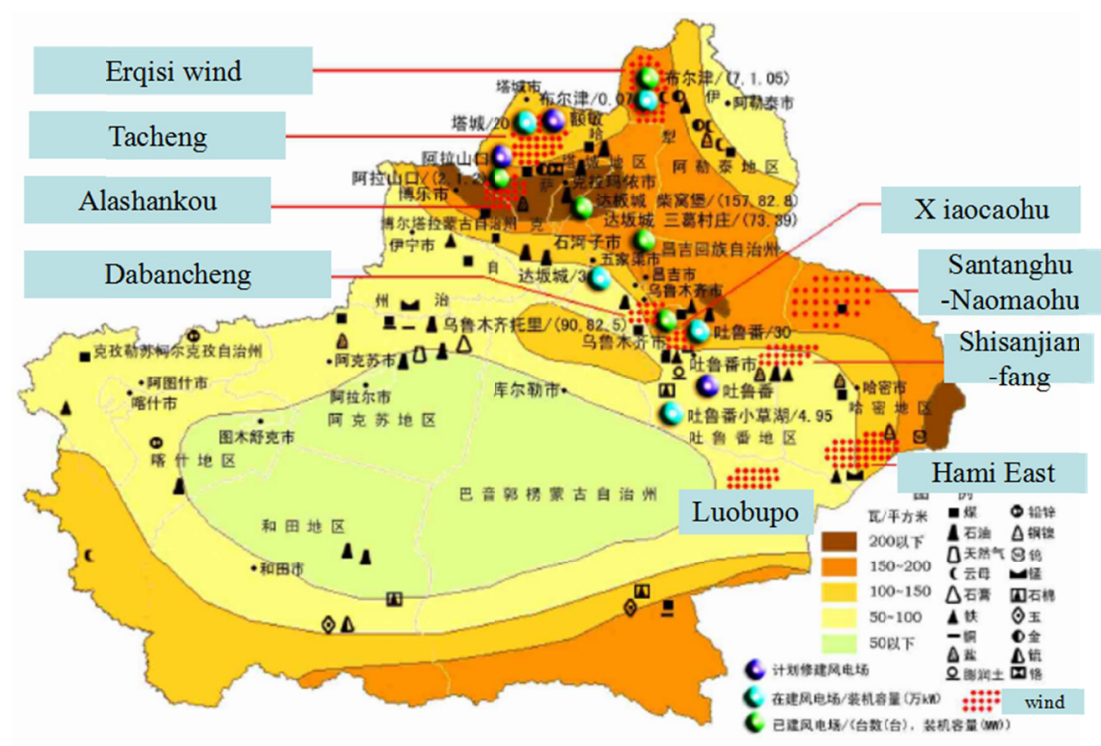


Figure 5. Distribution of wind energy density and the nine wind areas in Xinjiang

The Lop Nur wind zone and the southeast Hami wind area occupy 1.17 million $\mathrm{km}^{2}$, with a technical development of 0.16 million $\mathrm{kWh}$. The Turpan Xiaocaohu wind zone, which is the smallest with only $981.6 \mathrm{~km}^{2}$, can be developed to generate 2002 MW of electric power. Santanghu in NOM Hufeng District, which is the largest zone with an area of $34007 \mathrm{~km}^{2}$, can be developed to generate $48974 \mathrm{MW}$ of electric power ( $\mathrm{Li}$ et al., 2015, p.7).

The development and utilization of wind energy resources in Xinjiang are concentrated in the nine major wind zones, with a total area of 7.78 million $\mathrm{km}^{2}$. The annual average wind power density is $150 \mathrm{~W} / \mathrm{m}^{2}$, the annual average number of utilization hours is $2000-3600$ hours, and the technical exploitation amount is 1.2 million $\mathrm{kW}$ (Table 1).

Table 1. Wind energy resources data of Xinjiang's nine major wind areas (Source: Xinjiang Meteorological Bureau)

\begin{tabular}{|c|c|c|c|c|}
\hline No. & Name & $\begin{array}{l}\geq 150 \mathrm{~W} / \mathrm{m}^{2} \text { the measure of } \\
\text { area } \\
\left(\mathrm{km}^{2}\right)\end{array}$ & $\begin{array}{l}\geq 150 \mathrm{~W} / \mathrm{m}^{2} \\
\text { reserves }(\mathrm{MW})\end{array}$ & $\begin{array}{l}\text { Technology } \\
\text { development (MW) }\end{array}$ \\
\hline 1 & $\begin{array}{l}\text { Santanghu } \\
\text {-Naomaohu }\end{array}$ & 34007 & 62387 & 48974 \\
\hline 2 & Luobubo & 11708.2 & 20489 & 16084 \\
\hline 3 & Hami East & 11657 & 20400 & 16014 \\
\hline 4 & Shisanjianfang & 5905 & 13389 & 10510 \\
\hline 5 & Tacheng & 4013.6 & 10747 & 8436 \\
\hline 6 & Alashankou & 3311.4 & 9588 & 7526 \\
\hline 7 & Erqisi & 4276.2 & 8091 & 6351 \\
\hline 8 & Dabancheng & 1938 & 5249 & 4120 \\
\hline 9 & Xiaocaohu & 981.6 & 2550 & 2002 \\
\hline Total & & 77798 & 152890 & 120017 \\
\hline
\end{tabular}

Eleven wind power fields have been constructed around the nine wind zones (Fig. 6): (1) Urumqi Dabancheng, (2) Hami, (3) Burqin, (4) Mayidasi, (5) Allah Yamaguchi, (6) Yili, (7) Manas, (8) Mori, (9) Xiaocaohu, (10) Toksun, and (11) Ruoqiang Luobuzhuang wind farms.

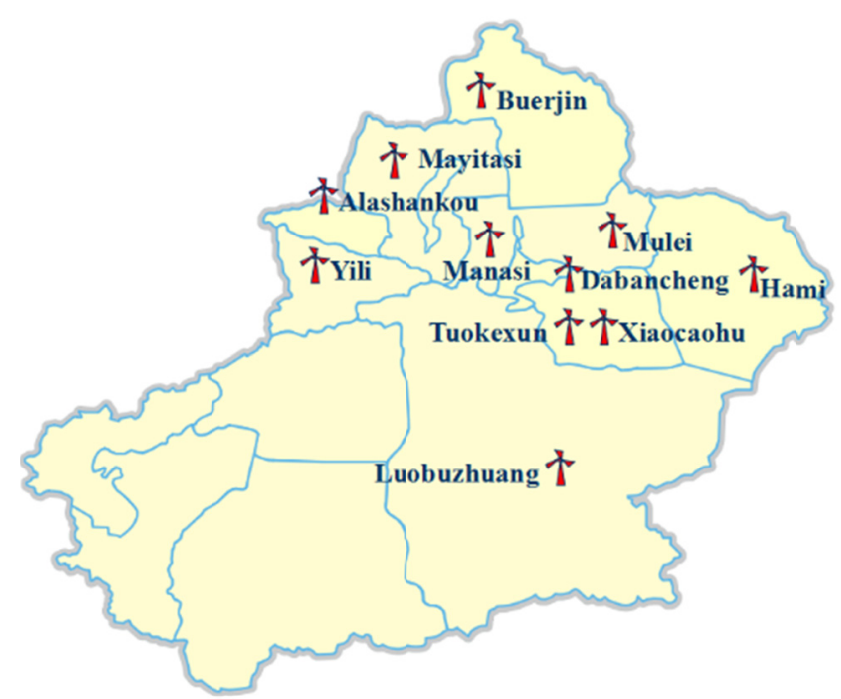

Figure 6. Distribution map of the 11 wind farms in Xinjiang

\subsection{Key Development Stages of Wind Power Industry in Xinjiang}

Xinjiang was one of the first provinces in China to develop its wind power industry. Since early 1982, Xinjiang has established many wind energy research institutions and conducted research and development of wind energy. 
The entire wind power development process in Xinjiang can be divided into four stages (Li, 2014).

Stage one: Initial stage (1982-1993). In 1982, Xinjiang Wind Power Research Institute was established, which was responsible for study and promotion of small fans. During the following 10 years, an off-grid small wind machine was put into operation in 1983, and 6000 small wind turbines were established by 1993 in the agricultural and pastoral areas of northern Xinjiang, which resolved the electricity problem for local farmers and herdsmen households. The early exploration of wind power in China yielded encouraging achievements. In December 1986, the Xinjiang Water Resources Department and a Danish wind energy company introduced a blower. In 1989, the same company introduced 13 sets of $150 \mathrm{~kW}$ blowers. The first wind power plant in China was established in Dabancheng in October 1989, overcoming difficulties such as lack of personnel, lack of experience, and atrocious weather. At that time, the total installed capacity of this power grid not only ranked first in China but was also the largest in Asia. This milestone marked that the wind power industry in China transited from the research \& development stage to the industrialization stage (Lin et al., 2010).

Stage two: Steady development stage (1994-2005). In 1994, the installed capacity of the Dabancheng wind farm exceeded 100 MW. Until 2005, Xinjiang was always among the top three of wind power generation in China. During this stage, the wind power industry in Xinjiang was at the forefront of China and developed steadily.

Stage three: Slow development stage (2006-2010). The promulgation of the Renewable Energy Law in 2005 prompted the rapid development of wind power in China. However, the development of the wind power industry in Xinjiang slowed down considerably and failed to keep up with the national pace. In 2006, the installed capacity in Xinjiang was only 20000MW, dropping from the first place to the sixth place in China, but in 2010, it further declined to the ninth place (13640MW), accounting for only $3 \%$ of total installed capacity in China.

Stage four: Rapid development stage (2011-present). Since 2010, both the central government and the Xinjiang government, at all administrative levels, have vigorously supported the development of the wind power industry in Xinjiang and formulated relevant incentive policies. In 2012, the state named Xinjiang as one of the nine largest wind power bases in China. Wind power enterprises have provided investments, personnel, financial support and technical assistance to the wind power industry in Xinjiang. By 2014, the wind power installed capacity in Xinjiang returned to top ranks.

At present, after more than 30 years of steady development, the wind power industry in Xinjiang has reached its peak. However, current development is still lagging and thus requires strong support by way of relevant incentive policies. Moreover, with the assistance from 19 provinces/cities in China, the wind power in Xinjiang appears to moving into a period of rapid development path.

Xinjiang is rich in wind energy resources and is one of the large-scale wind power bases in China. However, wind power was seriously abandoned in Xinjiang for many years. In 2014, the Chinese government implemented the "three bases and one channel energy development strategy" in Xinjiang. Afterwards, Xinjiang caught the state-level large-scale scenery base construction, grasped the renewable energy market, and basically controlled the abandoned wind problem. So far, the development of the wind power industry in Xinjiang remains in good condition. The installed capacity of wind power in Xinjiang increased during 2001-2014 (Fig. 7) (Lu et al.,2015).

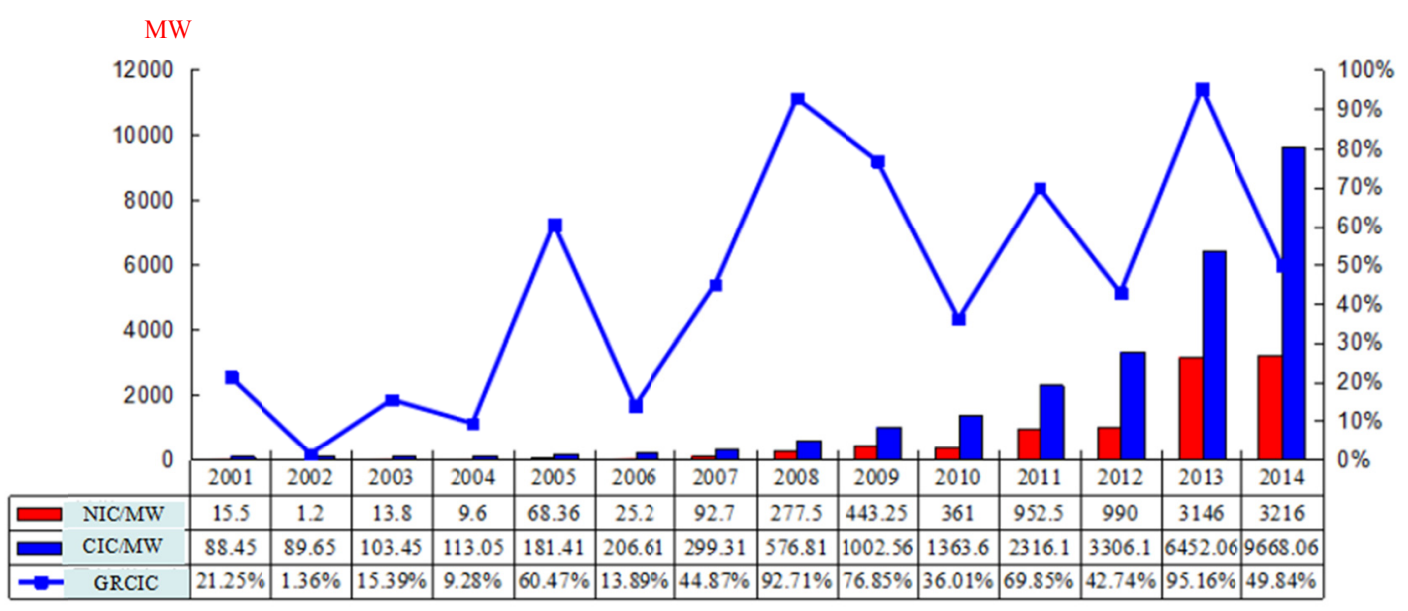

Figure 7. Installed capacity and growth of wind power in Xinjiang (2001-2014, MW) 
To promote energy-saving and emission reduction, improve the ecological environment, and adjust the energy structure, Xinjiang implemented the country grade scenery base construction in the nine wind zones (e.g. Urumqi Dabancheng, Hami Santanghu, Hami Nao Mao Hu, Turpan Xiaocaohu), four prefectures (e.g., Turpan, Hami), and areas rich in photovoltaic resources. By the end of 2015, the state approved the construction of wind power plants up to a scale of $18.83 \mathrm{GW}$ in Xinjiang. Meanwhile, the construction of photovoltaic plants reached $7.36 \mathrm{GW}$, which ranked second in China (Ma et al., 2009, p.3).

Statistics from Xinjiang Power Grids show that the installed capacity of the network operation of Xinjiang power grids reached $58369 \mathrm{MW}$ by the end of November 2015, with a growth of 36.94\% from 2014 and accounting for $17 \%$ of the total installed capacity in China. These statistics suggest that the national scenery base has been successfully built in Xinjiang and that the overall development is in good condition.

\subsection{Prominent Problems in High-Speed Development}

Xinjiang is rich in renewable energy resources, but the development and utilization require considerable attention. In 2014, the Central Committee of the second work in Xinjiang clearly proposed to transform the solar energy and wind energy advantages in Xinjiang into economic advantages, and to improve the national large-scale base construction of photovoltaic and wind power in Xinjiang. Photovoltaic power generation process is simple and efficient, and solar energy storage is abundant, and its distribution range is large. Statistics show that the power grid capacity of Xinjiang increased over four times during the "Twelfth Five-Year Plan". The installed capacity of wind power grew at an average annual rate up to $69 \%$, the average annual wind power capacity increased by $45.3 \%$, and solar power grew exponentially from scratch (Ma, 2010, p.2).

However, the development and utilization of new energy in Xinjiang highlight the problem of abandoned wind power rationing, which seriously affects the development of new energy. Large-scale renewable energy consumption is always a challenge worldwide. Renewable energy consumption problems in Xinjiang rank among the top three in China. Since 2012, the GDP of China has been growing annually, ushering the economy into the new normal level. Consequently, the electricity demand is also gradually slowing down. However, the installation speed of thermal power and renewable energy power plants in Xinjiang is extremely fast and considerably surpasses the development speed of power demand. By the end of November 2015, the total installed capacity of the Xinjiang power grid increased by $24.7 \%$, considerably higher than the electricity demand growth of $6.1 \%$. Such imbalance directly leads to a considerable decrease in renewable energy use and thermal power utilization hours, which increasingly intensifies the problem of abandoned wind power rationing (Sun et al., 2015).

\section{Analysis of and Strategy Research on Wind Power Curtailment}

\subsection{Causes of Abandoned Wind Power Rationing}

Statistics show that during the first 11 months of 2015, the wind power utilization hour was only 1595 hours, which was down by 276 hours. The total abandoned wind power rationing was up to 64.22 million $\mathrm{kWh}$, and the abandoned wind power rate hit a record high of $31.5 \%$ in Xinjiang, with an increase of $16.6 \%$ (Sin et al., 2015).

Abandoned wind power rationing, which is caused by multiple factors, becomes increasingly serious. Power grid construction lags behind the objective factors of the wind farm construction cycle, indicating the power structure of Xinjiang is unreasonable. Objective and historical factors, as well as new energy power generation price adjustment periods (i.e., winter heating period and coal price downturn period), comprised three overlapping factors that were unique in 2015. These unique temporary factors were the main causes for the exacerbation of the abandoned wind power rationing in Xinjiang. The specific reasons could be illustrated from four aspects (Xu et al., 2015).

(1) The power structure is unreasonable. Winter heating peak limits space.

Statistics show that thermal power in Xinjiang accounts for over $70 \%$ of the total supply. In terms of thermal power, privately-owned power plants provided over $45 \%$ but did not participate in heating peaking. The Xinjiang power grid unified power plant provides only $55 \%$ of the peak load system of a power plant, and heating units account for up to $56 \%$ higher than only in the transfer system of the power plant. Therefore, only $30 \%$ of the power plants can be used for peak shaving. Xinjiang is cold in winter, but the power load is low. To ensure that the heating unit of the output works normally, load space is limited and thus peaking capacity is lacking. Thus, winter heating in Xinjiang is one of the fundamental factors that affect abandoned wind power rationing (Xu et al., 2015).

(2) Prices, installation of wind power enterprises 
For our production in 2016, the wind power tariff was cut by 2 percent, and consequently, wind power companies accelerated the wind farm construction at the end of the 2015 production period. In 2015, the wind power project production and the installed capacity both increased, which are two direct and primary factors that affect the abandoned wind power rationing (Yuan et al., 2015, p.5).

(3) Limited electricity delivery market in Xinjiang

Henan province reduced electricity load because of the economy decline in China. Meanwhile, coal prices dropped sharply, which reduced the cost of thermal power. The price advantage of electricity delivery in Xinjiang was not too significant, which was weakened after the electric supply from Xinjiang to Henan was reduced. Consequently, a part of the distributed power was consumed only in local areas of Xinjiang, which considerably narrowed down the space of the renewable energy market in Xinjiang. These objective factors intensified the abandoned wind power rationing in Xinjiang in 2015 (Zhang et al., 2008, p.4).

(4) Power grid construction lags behind the wind farm construction; transport channels are limited

The majority of wind power systems in Xinjiang are concentrated far away from the load center, which extremely limits the local consumption space and leads to the long-distance electricity transmission of UHV. However, the wind power construction period is considerably shorter than the power grid distribution construction period (3-6 months vs. 12-18 months), which results in the wind power and power grid construction. Therefore, production is not synchronized. This important factor causes abandoned wind power rationing (Zhang et al., 2015).

From an objective perspective, the abandoned wind power rationing in Xinjiang requires additional attention. This phenomenon is mainly affected and exacerbated by multiple temporary factors. At present, the incidence of abandoned wind power rationing is high. However, the implementation of follow-up measures will gradually relieve this phenomenon. Overall, the national large-scale wind power development base is good.

In summary, large-scale wind energy generation in Xinjiang is concentrated far from the load center, so the consumption space is limited. After nearly two years of economic recovery, the power supply structure of the wind power concentrated area and electricity demand growth were slowed down. Wind power development and power grid construction are not synchronized. Deficiencies exist in the wind power market system, such as multiple factors that act collectively to cause the record high of abandoned wind power rationing. To solve the wind power consumption problem, the Xinjiang Development and Reform Commission, power grid companies, and new energy enterprises have participated in various pioneering innovative activities and measures.

\subsection{Measures to Solve the Abandoned Wind Power Rationing}

The principle of "market is the foundation, power grid is the condition, and reform is the solution" was applied to alleviate abandoned wind power cuts in Xinjiang. Various departments coordinate to actively adjust the structure of the energy industry. Strategies have been efficiently taken to enlarge the space of wind power consumption, including the research and development of potential power sources, and the delivery of channel construction measures.

(1) The overall planning of a power grid, ahead of its layout, increases peak shaving unit construction.

First, an advance layout of wind power and distribution channel construction is needed to satisfy the requirements of a wind power project and to gain fast approval. A short construction period is also recommended, so the simultaneous development of wind power and grid coordination should be promoted. Second, accelerating the construction of the Hami, Fukang, and Aktau pumped storage energy power plants will significantly enhance the peaking capacity of the grid system, and thus promote the coordinated development of wind power and thermal power.

(2) Simplify the power grid to strengthen power grid transmission capacity.

First, the acceleration of project construction has been approved for power distribution. By the end of 2015, $23750 \mathrm{kV}$ lines were built, with a total length of $4103 \mathrm{~km}$; a total of $18013 \mathrm{~km}$ of $220 \mathrm{kV}$ and a total length of $29007 \mathrm{~km}$ of $110 \mathrm{kV}$ were built. Second, to accelerate planning and construction of distribution channels, we need to advance the construction of scenery power transmission project 39, and coordinate Xinjiang power grid and the prefectures of time limit for a project, which ensure that the wind power and grid synchronization will be realized and put into operation.

(3) Strengthen power grid distribution and optimize the operation mode.

In accordance with relevant requirements of National Energy Bureau, we actively supervise the State Grid Electric Power Company of Xinjiang to conscientiously implement the Renewable Energy Law. Thus, we further 
increase energy-saving generation distribution, schedule digging potential, strengthen wind power base in the overall output of the predictive analysis and remote monitoring technology public relations. We also improve wind power scale use of intermittent, effectively improve utilization hours of wind power and other renewable energy equipment, and provide larger consumption space for wind power and other renewable energy sources.

(4) Wind electric heating power can be alternatively coupled with the coal chemical industry and oil well production, such as in microgrids, or the use of energy storage technology to enhance local consumption space.

By the end of 2015, the wind power heating project in Urumqi Dabancheng, Altay region was put into operation, generating 35 million $\mathrm{kW}$ of wind power through heating. The construction of the 45 other wind power heating projects was accompanied by the vigorous development of electric vehicles, electric boilers, heating cables, and wind cascade irrigation. Wind power was combined with transportation, construction, industry and agriculture, particularly for high-energy consuming industries. Wind electric was coupled with the coal chemical industry, oil exploitation, and wind power storage technology to enhance the consumption space and adjustment capability of wind power.

\subsection{Reforms and Innovations to Develop Wind Power}

To fundamentally solve the abandoned wind power rationing in Xinjiang, the electric power department and energy regulators must combine operation management with reforms and innovations to start electric power system reform, electric power trade innovation, and adjustment of power industrial development speed. The peaking capacity of market-oriented grid systems, the proportion of wind power generation, and the space of wind power consumption all increase.

(1) Development of management, participation of power plants in peak shaving

In accordance with the implementation of the electric power system reform guidance (in 2015, on the 9th) and the recommendations of the National Energy Bureau, privately-owned power plants should participate in the power grid peak shaving. According to calculations, if private-owned power plants take part in $10 \%$ of power grid peak shaving, wind power utilization will be improved.

(2) Deal with power generation, increase the size of direct power supply

To explore the capability of power generation, the wind power to the power generation part of the waste to the thermal power, thermal power enterprises are encouraged through the market-oriented economic compensation mechanism to increase wind power output. The direct supply scope and scale of wind electricity should be further expanded, along with large-scale electricity direct trading, and wind power companies are encouraged to expand wind power consumption channels.

\section{(3) Adjust the speed of development and realize an orderly development of wind power}

The scale and speed of wind power development should be appropriately adjusted according to the consumption power market so as to preserve consumption space during development. A huge turnaround does not occur in the current economic situation, since the consumption market does not have a large space. Priority should be given to the development of the wind power industry, and the scale and speed of thermal power construction should be appropriately mitigated, along with the reasonable planning and reconstruction of in-service burning coal motor group. In summary, for the healthy development of the wind power industry in Xinjiang, relevant enterprises should seek innovation through reform and development, and thus fundamentally solve the abandoned wind power rationing in Xinjiang.

\section{Conclusions and Prospects}

Wind power occupies an important position in the energy structure of Xinjiang. We introduced wind energy resources and the development of wind power industry in Xinjiang. We mainly analyzed the abandoned wind power rationing, which was caused by an irrational power supply structure, limited peak load space in winter heating systems, and reduced wind power price. Other important factors include limited electricity distribution and power grid construction lagging behind wind power development.

A comprehensive evaluation system for wind power in Hami was built using the improved analytic hierarchy and fuzzy comprehensive evaluation. Wind power utilization level was studied and analyzed using a wind farm in Hami as an example. The new synthetic evaluation system for wind power has some practical value.

In summary, influence on wind power was considered from three aspects including power supply, power grid, and power load. In terms of power supply, thermal power, hydropower, wind power, photovoltaic power, and other alternative sources are improved. In terms of power grid, power grid construction, transmission distance and coverage should all be improved. In terms of power load, implementation of electricity demand scheduling 
response, expansion of electrical channels, and the increase of electricity demand are needed to realize a high proportion of new energy consumption in Xinjiang.

The key is to establish a wind power market. However, the current electric power supply is normal. Xinjiang, Henan and other power bases reduce the benchmark price of local electricity, or otherwise market competition will be inexistent. Therefore, to win the market and open up market space, the wind power industry in Xinjiang should develop wind power technology, reduce the cost and prices, and compete with traditional energy sources.

At present, Xinjiang wind power consumption mainly relies on bundling delivery. However, special high-pressure delivery channel was only Hami South-Zhengzhou 800 kV DC. The Xinjiang power grid "the 13th Five-year" plan clearly points to 2020. The Xinjiang power grid will add four UHV DC transmission channels: Zhundong-Chengdu $\pm 1100 \mathrm{kV}$, quasi-East-Wannan $\pm 1100 \mathrm{kV}$, Hami North-Chongqing $800 \mathrm{kV}$, and Yili Pakistan $\pm 660 \mathrm{kV}$. Power will reach 50 million $\mathrm{kW}$ at that time, and Xinjiang power grid will become the largest provincial power grid and the largest external transmission channel in China (Chen, 2017). The role of technology advancements' spur in the wind energy sector, within the examined period of 2001-2014, the continuous innovation of wind power technology has also stimulated the large-scale development of the wind power industry, and the power generation has been expanding.

China advocates the concept of green and low-carbon development. Xinjiang is rich in renewable energy sources, and considerable room remains for development. In the near future, the new energy industry in Xinjiang will progress to large-scale development and efficient utilization. The new energy industry will attain a dominant position in the energy structure, but this requires efforts from various members of the society. China proposes the Global Energy Internet Strategy and vigorously promotes the development and utilization of clean energy. With the help of this strategy, Xinjiang, as a core area in the Silk Road Economic Zone, can provide large-scale electricity distribution, actively participate in optimal energy allocation with the neighboring countries of China, and promote the sustainable development of its wind power industry.

\section{Acknowledgment}

We would like to show gratitude to the sound supports by Development and Reform Committee of Xinjiang autonomous region.

\section{Conflict of interest}

The authors declare that they have no conflict of interest.

\section{References}

Chen, B. (2017). Analysis on the development prospect of wind power heating in Xinjiang area. Building Materials and Decoration, (25).

Fan, X. C., \& Wang, W. Q. (2016). Spatial patterns and influencing factors of China's wind turbine manufacturing industry: a review. Renew Sustain Energy Rev, 54, 482-496. https://doi.org/10.1016/j.rser.2015.10.020

Fan, X. C., Wang, W. Q., \& Shi, R. J. et al. (2015). Analysis and countermeasures of wind power curtailment in China. Renewable \& Sustainable Energy Reviews, 52, 1429-1436. https://doi.org/10.1016/j.rser.2015.08.025

Fan, X. C., Wang, W. Q., Shi, R. J., \& Li, F. T. (2015). Review of developments and insights into an index system of wind power utilization level. Renew Sustain Energy Rev, 48, 463-471. https://doi.org/10.1016/j.rser.2015.04.003

Gosens, J., \& Lu, Y. (2013). From lagging to leading? Technological innovation systems in emerging economies and the case of Chinese wind power. Energy Policy, 60(6), 234-250. https://doi.org/10.1016/j.enpol.2013.05.027

Guo, Y., Ru, P., Su, J., \& Anadon, L. D. (2015). Not in my backyard, but not far away from me: Local acceptance of wind power in China. Energy, 82, 722-733. https://doi.org/10.1016/j.energy.2015.01.082

He, Y., Pang, Y., \& Zhang, J. et al. (2015). Feed-in tariff mechanisms for large-scale wind power in China [J]. Renewable \& Sustainable Energy Reviews, 51, 9-17. https://doi.org/10.1016/j.rser.2015.05.084

Heya, B., \& Chen, H. (2015). Application and Development Prospect of Wind and Photovoltaic Power Generation in Xinjiang. Control \& Instruments in Chemical Industry.

Huber, M., \& Weissbart, C. (2015). On the optimal mix of wind and solar generation in the future Chinese power system. Energy, 90, 235-243. https://doi.org/10.1016/j.energy.2015.05.146 
Li, C. B., Chen, H. Y., Zhu, J., Zuo, J., Zillante, G., \& Zhao, Z. Y. (2015). Comprehensive assessment of flexibility of the wind power industry chain. Renew Energy, 74, 18-26. https://doi.org/10.1016/j.renene.2014.07.045

Li, J. (2014). China Wind Power Review and Outlook. Beijing: China Environmental Science Press.

Lin, X., \& Fang, C. (2010). Study on the actuality and countermeasure of 10 Million Kilowatts Wind Power Industry Base in Jiuquan. World Non-Grid-Connected Wind Power and Energy Conference (WNWEC), 2010. IEEE, 1-6. https://doi.org/10.1109/WNWEC.2010.5673602

Liu, Y., Ren, L., Li, Y., \& Zhao, X. G. (2015). The industrial performance of wind power industry in China. Renew Sustain Energy Rev, 43, 644-655. https://doi.org/10.1016/j.rser.2014.11.003

Lu, Z. Y., Li, W. H., Xie, B. C., \& Shang, L. F. (2015). Study on China's wind power development path-Based on the target for 2030. Renew Sustain Energy Rev, 51, 197-208. https://doi.org/10.1016/j.rser.2015.06.024

Luo, G. L., Li, Y. L., Tang, W. J., Wei, X., \& Kazmerski, L. (2016). Wind curtailment of China's wind power operation: Evolution, causes and solutions. Renew Sustain Energy Rev, 53, 1190-1201. https://doi.org/10.1016/j.rser.2015.09.075

Ma, F. F., Chang, X. Q., \& Cai, P. C. (2009). Inspiration of Xinjiang Power Grid Operation Based on Wind Power Generation to Development and Construction of Wind Power. Sichuan Electric Power Technology, 32(4), 57-61.

Ma, G. M. (2010). Analysis on the development trend of Xinjiang wind power industry. Modern Economic Information, (17), 205-207.

Sun, S., Liu, F., Xue, S., Zeng, M., \& Zeng, F. (2015). Review on wind power development in China: Current situation and improvement strategies to realize future development. Renew Sustain Energy Rev, 45, 589-599. https://doi.org/10.1016/j.rser.2015.02.018

Xin, Y., Yu, X., \& Chen, H. (2015). Verification of Wind Forecasts at Funneling Wind Area in Xinjiang by Two Background Field Improving Schemes. Journal of Desert Research.

Xu, C., Li, J., Zhao, J., Gao, S., \& Chen, Y. (2015). Climate variations in northern Xinjiang of China over the past 50 years under global warming. Quaternary International, 358, 83-92. https://doi.org/10.1016/j.quaint.2014.10.025

$\mathrm{Xu}, \mathrm{S}$., Wu, P., \& Zhao, B. et al. (2015). Study on the security and stability control strategy enhancing the wind power consuming ability of the wind-thermal power combining Hazheng UHVDC system. Diangong Jishu Xuebao/transactions of China Electrotechnical Society, 30(13), 92-99.

Yuan, X., Zuo, J., \& Huisingh, D. (2015). Social acceptance of wind power: a case study of Shandong Province, China. Journal of Cleaner Production, 92, 168-178. https://doi.org/10.1016/j.jclepro.2014.12.097

Zhang, Q. (2008). Developmental Approach and Strategy of Large-scale Grid and off-Grid Wind Power Industries in Xinjiang. Resources Science, 30(11), 1677-1683.

Zhang, S., Wang, W., Wang, L., \& Zhao, X. (2015). Review of China's wind power firms internationalization: Status quo, determinants, prospects and policy implications. Renew Sustain Energy Rev, 43, 1333-1342. https://doi.org/10.1016/j.rser.2014.11.100

\section{Copyrights}

Copyright for this article is retained by the author(s), with first publication rights granted to the journal.

This is an open-access article distributed under the terms and conditions of the Creative Commons Attribution license (http://creativecommons.org/licenses/by/4.0/). 